This document is the accepted manuscript version of the following article: Meegan, J. E., Yang, X., Rungsirisakun, R., Cosgrove, S. C., Bushby, R. J., Sadeghpour, A., Rappo1t, M., Brydson, R., \& Anse11, R. J. (2017). Synthesis and organogelating behaviour of amino acid-functionalised triphenylenes. Soft Matter, 13(35), 5922-5932. https://doi.org/10.1039/C7SM00676D

\title{
Synthesis and organogelating behaviour of amino acid-functionalised triphenylenes
}

\author{
Jonathan. E. Meegan ${ }^{a, ~}, d$, Xiaofei Yang ${ }^{a, e}$, Ratana Rungsirisakun ${ }^{a, f}$, Sebastian C. Cosgrove ${ }^{a}$, \\ Richard J. Bushby ${ }^{a}$, Amin Sadeghpour ${ }^{b, g}$, Michael Rappolt ${ }^{b}$, Rik Brydson ${ }^{c}$ and Richard J. \\ Ansell*a
}

Four novel amino acid-functionalised triphenylenes have been prepared with glycine, Lalanine, L-phenylalanine and L-tryptophan ethyl ester side-chains. The glycine derivative is a good gelator of chloroform, the alanine derivative gels ethanol and toluene, and the phenylalanine derivative gels benzene and toluene. The tryptophan derivative does not gel any of the solvents tested, most probably due to its more bulky structure, but forms microspheres by evaporation-induced self-assembly.

The self-assembly properties of the $\pi$-gelators have been investigated using infrared, UVabsorption and fluorescence spectroscopy, concentration- and temperature-dependent NMR, and X-ray scattering experiments on dried xerogel as well as the wet organogel. The latter experiments suggest the glycine gel in chloroform includes columnar aggregates, with an overall disordered columnar oblique mesophase. These compounds are of interest because of the well-known hole-transporting properties of triphenylene liquid crystals: 1-D columnar assemblies of these compounds may find applications in organic electronic devices.

\section{Introduction}

Triphenylene derivatives form a class of discotic mesogens capable of one-dimensional faceto-face assembly into columnar stacks. Since the report of their self-assembly properties in $1978^{1}$, they have been the focus of many investigations because of the possibility of onedimensional conductivity along the stack of overlapping $\pi$-electron systems. Applications have been proposed in electrophotography and organic electronics ${ }^{2}$, organic $\mathrm{LEDs}^{3}$, optoelectronics $^{4}$, surface modification ${ }^{5}$, chemical sensing ${ }^{6}$, as optical compensating films for increasing the angle of view of liquid crystal displays ${ }^{7}$, for controlling aggregation of nanoparticles ${ }^{8}$ and the templating of inorganic mesostructures ${ }^{9}$. Recently other applications for triphenylene derivatives (not dependent on the self-assembly properties) have been suggested, as covalent scaffolds for organised macromolecular structures ${ }^{10}$, molecular receptors ${ }^{11}$ and drug-delivery systems ${ }^{12}$. All these applications rely on rational modification of the molecular properties via the tailoring of the triphenylene side-chains.

Although most of the work aiming at applications in devices has focussed on thermotropic

\footnotetext{
$\overline{{ }^{a} \text { School of Chemistry, University of Leeds, Woodhouse Lane, Leeds LS2 }}$

9JT, UK Fax: +44 113343 6565; Tel: +44 113343 6415; E-mail:

chmrja@leeds.ac.uk

${ }^{b}$ School of Food Science and Nutrition, University of Leeds.

${ }^{c}$ School of Chemical and Process Engineering, University of Leeds.

${ }^{d}$ present address: Solvay Composite Materials, Wrexham, UK.

${ }^{e}$ present address: School of Materials Science and Engineering, Jiangsu University, Zhenjiang, China.

${ }^{f}$ present address: Institute of Materials Sciences and Engineering Research, King Mongkut's University of Technology Thonburi, Bangkok, Thailand.

${ }^{g}$ present address: Empa - Swiss Federal Laboratories for Materials Science and Technology, St. Gallen, Switzerland
} 
triphenylenes, which form liquid crystalline structures as homogeneous materials or blends with other components, there has been an increasing number of triphenylenes reported with lyotropic liquid crystal and/or solvent gelating properties. The first of these was 2,3,6,7,10,11-hexa-(1,4,7-trioxaoctyl)-triphenylene (TP6EO2M), which forms hydrogels / lyotropic phases in water ${ }^{13,14,15}$. Subsequently several triphenylene derivatives have been reported which are capable of gelating organic solvents $6,16,17,18,19,20,21,22,23,24,25,26$, while others have been shown to form physical gels in combination with an additional gelator ${ }^{27}$. This reflects an increasing interest in low molecular weight organogelators (LMOGs) generally $^{28}$, and $\pi$-gelators in particular ${ }^{29}$, due to their manifold potential technological applications. In all the triphenylene organogels reported, the structure is proposed to include columnar stacks of triphenylene derivatives, with the side-chains playing an essential role via hydrogen bonding or ionic interactions which reinforce the relatively weak $\pi-\pi$ interactions and help to maintain the columnar organisation. However, while the columnar structures of thermotropic liquid crystal triphenylenes have been demonstrated in many cases by smalland wide- angle X-ray scattering experiments (WAXS and SAXS), these experiments are much more difficult on lyotropic/organogel systems, and the structure of the triphenylene organogels has mostly been investigated by solution methods such as absorbance / fluorescence spectroscopy, by X-ray studies of dried gels (xerogels), or by extrapolating from the thermotropic behaviour of the pure compounds. Only one example of X-ray measurements on an organogelating triphenylene in the lyotropic state has been reported, by Mendes et al. ${ }^{22}$, giving rather broad scattering peaks at about 25 and $14 \AA$ which were attributed to the distance between columns, but could not be assigned to any particular packing arrangement.

Peptide gelators are well known ${ }^{30}$ and several reports have attempted to combine $\pi$-gelators with amino acids or peptides, to create novel, functional, biomimetic structures, for example using perylene bis(imide)s $\mathrm{s}^{31}$ and other $\pi$-gelator derivatives ${ }^{32}$. Inspired by this vision of functional biomaterials, we designed and synthesised novel compounds 2a-2d (Fig. 1), incorporating glycine, L-alanine, L-phenylalanine and L-tryptophan respectively, using a modular approach which will be adaptable to the synthesis of a large range of new triphenylenes. Use of amino acids provides an inexpensive approach to introduce chirality into the side-chains. Although Stoddart et al. reported sugar-appended triphenylenes capable of forming lyotropic mesophases with organic solvents back in $2001^{16}$, and others have reported organogelating triphenylenes containing amide groups ${ }^{17,19,20,21,24}$, the only previous reports of triphenylene-amino acid conjugates of which we are aware are three compounds reported by Bechgaard et al. in $1997^{33}$ but not investigated for lyotropic behaviour (the tertbutyl, rather than ethyl, derivatives of $\mathbf{2} \mathbf{a}$ and $\mathbf{2} \mathbf{b}$, and the deprotected carboxylic acid variant of $\mathbf{2 b}$ ), and a recently reported triphenylene-homoserine conjugate whose self-assembly properties have not yet been reported ${ }^{34}$. Only two examples have been reported of triphenylene organogelators with chiral side-chains ${ }^{16,20}$. Thus, the amino-acid functionalised triphenylenes 2a-2d, studied in this work, comprise the first members of an interesting new class of compounds.

Furthermore, we report also on the organogelating behaviour of these compounds, including SAXS studies on $\mathbf{2 a}, \mathbf{2 b}$ and $\mathbf{2 c}$ in the lyotropic state. The diffraction pattern for the gel of $\mathbf{2 a}$ in chloroform is consistent with a disordered columnar oblique $\left(\mathrm{Col}_{\mathrm{o}}\right)$ structure, which is also 
evident in the powder diffraction pattern of the dried xerogel. This is, to our knowledge, the first X-ray study of the structure of a triphenylene in the lyotropic state apart from a preliminary result with TP6EO2M in $\mathrm{D}_{2} \mathrm{O}$ published in $1986^{13}$ and the work of Mendes et al. ${ }^{22}$. Further, ours is the first where a definitive structure can be assigned to the inter-columnar organization.

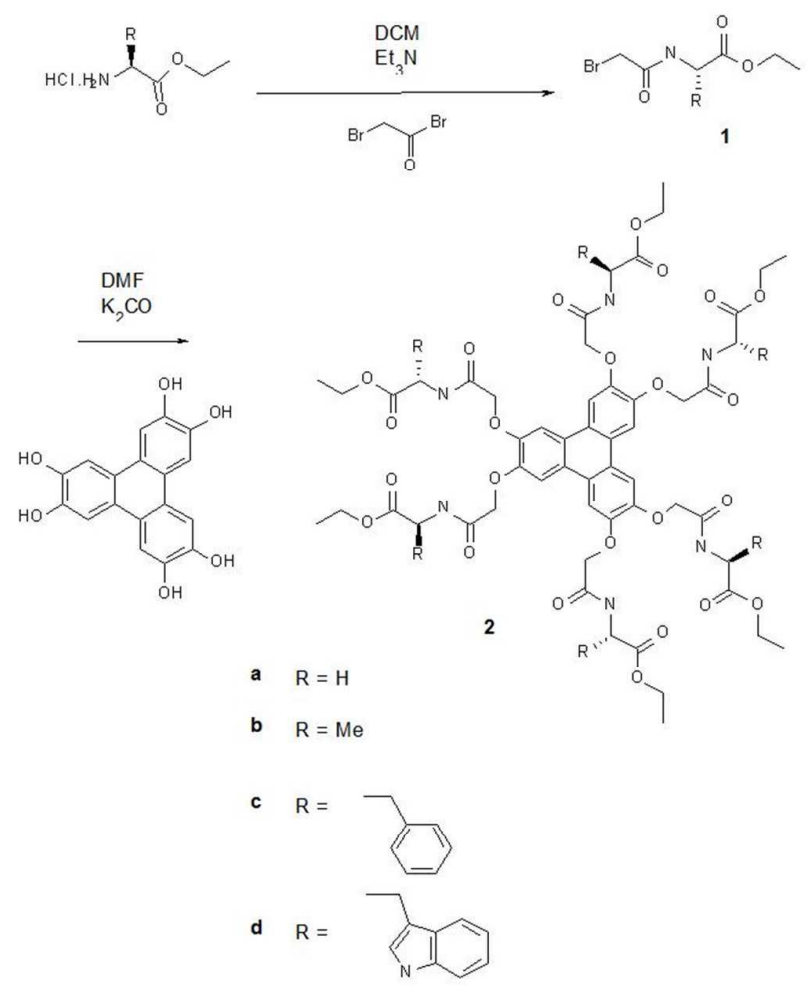

Figure 1. Synthesis of amino acid-functionalised triphenylenes $\mathbf{2 a - 2 d .}$

\section{Experimental}

\section{Instruments}

${ }^{1} \mathrm{H}$ NMR investigations were conducted on a Bruker Avance 500 operating at $500 \mathrm{MHz}$. For variable temperature experiments, samples were kept in the magnet at the set temperature for $10 \mathrm{~min}$ prior to the collection of data. UV absorbance spectra were recorded on an Agilent Carey $100 \mathrm{UV}$-Vis spectrophotometer using $1 \mathrm{~mm}$ pathlength quartz cuvettes. Fluorescence spectra were recorded on a Jobin Yvon Horiba Fluorolog 2 spectrofluorimeter, using $10 \mathrm{~mm} \times 10 \mathrm{~mm}$ quartz fluorescence cuvettes in the front-face configuration (to minimise inner filter effects), excitation was at $320 \mathrm{~nm}$ and slit widths were $0.5 \mathrm{~nm}$. SEM secondary electron micrographs were obtained on a Carl Zeiss/LEO 1530 field emission scanning electron microscope (FEGSEM) operated at low $\mathrm{kV}$ and using an in lens detector. Powder X-ray diffraction analyses were performed with a Bruker D8 Advance A25 diffractometer using $\mathrm{Cu}-\mathrm{K} \alpha$ radiation $(\lambda=0.15418 \mathrm{~nm})$. The 
optical microscope was a Seben SBX-V Microscope 40×-2000×, equipped with a Seben PC USB eyepiece. FTIR spectra were collected using a Thermo Scientific Nicolet iS5 spectrometer with an iD1 transmission cell. Samples were contained in a liquid cell comprising $\mathrm{NaCl}$ windows separated by a $500 \mu \mathrm{m}$ teflon spacer. Samples in gelling solvents were heated until completely dissolved before filling the cell and allowing them to cool.

\section{Gelation studies}

Gelation studies were carried out by dissolving triphenylene $(1 \mathrm{mg})$ in solvent $(50-800$ $\mu \mathrm{l})$. The triphenylene was dissolved with heating in a sealed $2 \mathrm{ml}$ glass vial (vials were held in an ultrasonic bath at $50 \mathrm{C}$ for c $2 \mathrm{~min}$, then in an oil bath set to the solvent's boiling temperature for $30 \mathrm{~s}$, for up to 5 cycles) and then left at room temperature for $1 \mathrm{~h}$. To test for gelation the vial was inverted. For SEM studies a small sample was removed and smeared onto an SEM stub (aluminium, $10 \mathrm{~mm}$ diameter), dried at room temperature under vacuum, and gold coated $(20 \mathrm{~mA}$ current, $20 \mathrm{~s}$ coating time at 5 Torr $)$ prior to placement in an SEM.

\section{SAXS}

A SAXSpace system (Anton Paar, Graz, Austria) with an X-ray generator from GE Inspection Technologies generating $\mathrm{Cu}-\mathrm{K} \alpha$ radiation (wavelength $\lambda=0.15418 \mathrm{~nm}$ ) was used. Disposable quartz capillaries (Capillary Tube Supplies Ltd, Cornwall, UK) were filled with samples in liquid state and sealed with Seal Wax Red (Tesco, UK). The capillaries were embedded into a homemade stainless holder which itself fits into the sample stage in SAXSpace. The sample stage is equipped with a Peltier element (TCStage 150, Anton Paar, Graz, Austria) controlling the temperature with a precision of $0.1^{\circ} \mathrm{C}$. While the X-ray exposure time for each measurement was 30 minutes, the overall scattering pattern was obtained after integration and averaging of three consecutive recorded scattering profiles.

The scattering patterns were corrected with respect to the position of the primary beam using the SAXStreat software (Anton Paar, Graz, Austria). The relative intensity of scattering data was further corrected using the transmittance of the X-ray beam at zero angles and setting its attenuated scattering intensity to unity. Background subtraction was carried out considering both the scattering from empty and solvent-filled capillaries. All these corrections were made using the SAXSQuant software (Anton Paar, Graz, Austria).

\section{Synthesis of materials}

Veratrole, $\mathrm{FeCl}_{3}$, bromoacetyl chloride, glycine ethyl ester hydrochloride, Lphenylalanine ethyl ester hydrochloride, L-tryptophan ethyl ester hydrochloride, $\mathrm{Et}_{3} \mathrm{~N}$, $\mathrm{K}_{2} \mathrm{CO}_{3}$ and $\mathrm{AcOH}$ were purchased from Sigma-Aldrich (Gillingham, UK). L-alanine ethyl ester hydrochloride was from Alfa Aesar (Heysham, UK). Deionised water was used throughout. Dimethylformamide (DMF) was purchased as anhydrous grade. 
Dichloromethane (DCM) was dried by continuous distillation over calcium hydride. Other solvents were from varied suppliers and at least HPLC grade. Column chromatography was carried out on silica (40-60 nm, Sigma-Aldrich).

Hexahydroxy triphenylene (HAT-0): Hexahydroxy triphenylene was prepared from veratrole $(55.3 \mathrm{~g}, 0.4 \mathrm{~mol})$ and $\mathrm{FeCl}_{3}(165 \mathrm{~g}, 1 \mathrm{~mol})$ according to the method described by Bechgaard et al. ${ }^{33}$. Pure hexahydroxy triphenylene was recrystallised from a solution of the crude product in acetic acid and water $(800 \mathrm{~mL}, 1: 1.5 \mathrm{v} / \mathrm{v})$ as a dark grey crystalline powder $(21 \mathrm{~g}, \mathrm{mmol}, 90 \%)$. $\delta_{\mathrm{H}}\left(\mathrm{DMSO}-d_{6}\right) 7.6(\mathrm{~s}, 6 \mathrm{H} \mathrm{ArH}), 9.33$ (broad s, 6H ArOH). Anal. Calcd. for $\mathrm{C}_{18} \mathrm{H}_{12} \mathrm{O}_{6} . \mathrm{C}_{2} \mathrm{H}_{4} \mathrm{O}_{2}$ (acetate): C, 62.60; H, 4.20. Found: C, 62.90; H, $4.20 \%$.

2-(2-Bromo-acetylamino)-acetic acid ethyl ester (1a): The glycine intermediate was made by a similar procedure to that of Lipowski et al. ${ }^{35}$, syntheses have also been reported by Kaverzneva et al. $^{36}$ and Zhang et al. ${ }^{37}$ Bromoacetyl bromide $(4.34 \mathrm{~mL}, 50 \mathrm{mmol}$ ) was added dropwise to a magnetically stirred solution of glycine ethylester hydrochloride $(6.14 \mathrm{~g}, 44 \mathrm{mmol})$ and $\mathrm{Et}_{3} \mathrm{~N}(12.2 \mathrm{~mL}, 88 \mathrm{mmol})$ in dry DCM $(100 \mathrm{~mL})$ and stirred under Ar for $3 \mathrm{~h}$ at $0{ }^{\circ} \mathrm{C}$. The solution was allowed to warm to room temperature overnight. The reaction was quenched at room temperature by addition of water $(100 \mathrm{~mL})$ and separated. The DCM extracts were washed with water $(100 \mathrm{ml}), \mathrm{HCl}(1 \mathrm{M}, 100 \mathrm{~mL})$, water $(100$ $\mathrm{mL}), \mathrm{NaHCO}_{3}(100 \mathrm{~mL})$, brine $(100 \mathrm{~mL})$, dried $\left(\mathrm{MgSO}_{4}\right)$ and concentrated in vacuo to yield the bromoamide as yellow/white solids which were used without further purification. The crude product could be purified by flash column chromatography $\left(\right.$ EtOAc $\left./ \mathrm{CHCl}_{3} 1: 1 \mathrm{v} / \mathrm{v}\right)$ to give the bromoamide as a white solid $(6.40 \mathrm{~g}, 28.6 \mathrm{mmol}$, $65 \%) . \delta_{\mathrm{H}}\left(\mathrm{CDCl}_{3}\right) 1.30\left(\mathrm{t}, 3 \mathrm{H}, \mathrm{CH}_{3} \mathrm{CH}_{2} \mathrm{O}\right), 3.92\left(\mathrm{~s}, 2 \mathrm{H}, \mathrm{BrCH}_{2} \mathrm{C}=\mathrm{O}\right), 4.08(\mathrm{~m}, 2 \mathrm{H}$, $\left.\mathrm{NHCH}_{2} \mathrm{C}=\mathrm{O}\right), 4.26\left(\mathrm{q}, 2 \mathrm{H}, \mathrm{CH}_{3} \mathrm{CH}_{2} \mathrm{O}\right), 6.95-7.06\left(\mathrm{~d}, 1 \mathrm{H}, \mathrm{O}=\mathrm{CNHCH}_{2}\right)$. Analytical data in agreement with literature ${ }^{35}$.

L-2-(2-Bromo-acetylamino)-propionic acid ethyl ester (1b): The alanine intermediate was previously prepared by Kaverzneva et al. ${ }^{36}$, although those authors used sodium carbonate as a base and published limited characterization data. Palsson et al. used this compound as an intermediate ${ }^{38}$, although they give no details of its synthesis or characterization. Bromoacetyl bromide $(5.22 \mathrm{~mL}, 60 \mathrm{mmol})$ was added dropwise to a magnetically stirred solution of L-alanine ethylester hydrochloride $(6.14 \mathrm{~g}, 40 \mathrm{mmol})$ and $\mathrm{Et}_{3} \mathrm{~N}(11.2 \mathrm{~mL}, 80$ $\mathrm{mmol})$ in dry DCM $(100 \mathrm{~mL})$ and stirred under Ar for $15 \mathrm{~h}$ at room temperature. The reaction was worked up in a similar manner to the glycine intermediate above to yield the bromoamide as yellow/white solids which were used without further purification. The crude product could be purified by flash column chromatography (EtOAc/ $\mathrm{CHCl}_{3} 1: 1 \mathrm{v} / \mathrm{v}$ ) to give the bromoamide as a white solid which was shown by NMR to be an intractable mixture of $95 \%$ bromo- and $5 \%$ chloro-derivatives $(6.38 \mathrm{~g}, 26.8 \mathrm{mmol}, 67 \%)$. $[\alpha]_{\mathrm{D}}=$ $+24.3\left(\mathrm{c} 0.84, \mathrm{CHCl}_{3}\right)$.

$\delta_{\mathrm{H}}\left(\mathrm{CDCl}_{3}\right) 1.30\left(\mathrm{t}, 3 \mathrm{H}, \mathrm{CH}_{3} \mathrm{CH}_{2} \mathrm{O}\right), 1.45\left(\mathrm{~d}-\mathrm{d}, 3 \mathrm{H}, \mathrm{CH}_{3} \mathrm{CHNH}\right), 3.89\left(\mathrm{~s}, 2 \mathrm{H}, \mathrm{BrCH}_{2} \mathrm{C}=\mathrm{O}\right)$, $4.23\left(\mathrm{q}, 2 \mathrm{H}, \mathrm{CH}_{3} \mathrm{CH}_{2} \mathrm{O}\right), 4.56(\mathrm{~m}, 1 \mathrm{H}, \mathrm{NHCHC}=\mathrm{O}), 7.03-7.13(\mathrm{~d}, 1 \mathrm{H}, \mathrm{O}=\mathrm{CNHCH}) ; \delta_{\mathrm{C}}$ $\left(\mathrm{CDCl}_{3}\right)$ 14.1, 18.3, 28.8, 48.5, 61.8, 165.1, 172.4; MS (ES): $m / z$ 238.0071, expect 238.0079 for $\left[\mathrm{MH}^{+}\right]$. Anal. calcd. for $\mathrm{C}_{7} \mathrm{H}_{12} \mathrm{BrNO}_{3}$ : C 35.3, H 5.08, N 5.88; Found C 35.2, H 5.10, N $7.90 \%$. 
L-2-(2-Bromo-acetylamino)-3-phenyl-propionic acid ethyl ester (1c): The phenylalanine intermediate was previously prepared by Gibb et $a .^{39}$, although those authors used acetonitrile as solvent and sodium carbonate as a base. Kaverzneva et al. ${ }^{36}$ also reported a synthesis using dichloromethane as solvent and sodium carbonate as base, but published limited characterization data. The intermediate was synthesised similarly to the alanine intermediate, except $3.48 \mathrm{~mL}(40 \mathrm{mmol})$ bromoacetyl bromide and $10.0 \mathrm{~mL}(72 \mathrm{mmol})$ $\mathrm{Et}_{3} \mathrm{~N}$ were used, and L-phenylalanine ethylester hydrochloride $(8.54 \mathrm{~g}, 36 \mathrm{mmol})$ was used in place of L-alanine ethylester hydrochloride to yield the bromoamide as a dark grey oil. The crude product was purified on a flash silica column $\left(1: 4 \mathrm{v} / \mathrm{v}\right.$ EtOAc/ $\left./ \mathrm{CHCl}_{3}\right)$ to yield a light green solid which was shown by NMR to be an intractable mixture of $70 \%$ bromo- and 30\% chloro-derivative (6.78 g, $21.6 \mathrm{mmol}, 60 \%)$.

$\delta_{\mathrm{H}}\left(\mathrm{CDCl}_{3}\right) 1.25\left(\mathrm{t}, 3 \mathrm{H}, \mathrm{CH}_{3} \mathrm{CH}_{2} \mathrm{O}\right), 3.15\left(\mathrm{~d}, 2 \mathrm{H}, \mathrm{CHCH}_{2} \mathrm{ArH}_{2}\right), 3.85\left(\mathrm{~s}, 2 \mathrm{H}, \mathrm{BrCH}_{2} \mathrm{C}=\mathrm{O}\right)$, $4.17\left(\mathrm{q}, 2 \mathrm{H}, \mathrm{CH}_{3} \mathrm{CH}_{2} \mathrm{O}\right), 4.83\left(\mathrm{q}, 1 \mathrm{H}, \mathrm{NHCH}\left(\mathrm{CH}_{2}\right) \mathrm{C}=\mathrm{O}\right), 6.88\left(\mathrm{~d}, 1 \mathrm{H}, \mathrm{O}=\mathrm{CNHCH}_{2}\right), 7.0-$ $7.65(\mathrm{~m}, 5 \mathrm{H}, \mathrm{ArH})$. Analytical data in agreement with literature ${ }^{39}$.

L-2-(2-Bromo-acetylamino)-3-(1H-indol-3-yl)-propionic acid ethyl ester (1d): The tryptophan intermediate was previously prepared by Pop et al. ${ }^{40}$, although those authors used sodium carbonate as a base and published no characterization data. The intermediate was synthesised similarly to the alanine intermediate, except $4.0 \mathrm{~mL}$ (46 mmol) bromoacetyl bromide and $8.4 \mathrm{~mL}\left(60 \mathrm{mmol}_{)} \mathrm{Et}_{3} \mathrm{~N}\right.$ were used, and L-tryptophan ethylester hydrochloride $(8.08 \mathrm{~g}, 30 \mathrm{mmol})$ was used in place of L-alanine ethylester hydrochloride to yield the bromoamide as a dark grey oil. The crude product was purified on a flash silica column $\left(1: 4 \mathrm{v} / \mathrm{v}\right.$ EtOAc/ $\left.\mathrm{CHCl}_{3}\right)$ to yield a grey/yellow solid which was shown by NMR to be an intractable mixture of $95 \%$ bromo- and $5 \%$ chloro-derivatives $(4.46 \mathrm{~g}, 12.6$ mmol, $42 \%) \cdot[\alpha]_{\mathrm{D}}=+22.8\left(\mathrm{c} 1.0, \mathrm{CHCl}_{3}\right)$

$\delta_{\mathrm{H}}\left(\mathrm{CDCl}_{3}\right) 1.22\left(\mathrm{t}, 3 \mathrm{H}, \mathrm{CH}_{3} \mathrm{CH}_{2} \mathrm{O}\right), 3.36\left(\mathrm{~m}, 2 \mathrm{H}, \mathrm{CHCH}_{2} \mathrm{ArH}_{2}\right), 3.82\left(\mathrm{~s}, 2 \mathrm{H}, \mathrm{BrCH}_{2} \mathrm{C}=\mathrm{O}\right)$, 4.15 (q, 2H, $\left.\mathrm{CH}_{3} \mathrm{CH}_{2} \mathrm{O}\right), 4.88\left(\mathrm{~m}, 1 \mathrm{H}, \mathrm{NHCH}\left(\mathrm{CH}_{2}\right) \mathrm{C}=\mathrm{O}\right), 6.94\left(\mathrm{~d}, 1 \mathrm{H}, \mathrm{O}=\mathrm{CNHCH}_{2}\right), 7.0$ - 7.65 (m, 5H, $A r H), 8.21$ (s, 1H, NH). MS (ES): $m / z$ 353.0481, expect 353.0501 for $\left[\mathrm{MH}^{+}\right]$. Anal. Calcd. for $\mathrm{C}_{15} \mathrm{H}_{17} \mathrm{O}_{3} \mathrm{~N}_{2} \mathrm{Br}$ : C, 51.00; H, 4.85; N, 7.93. Found C, 51.20; H, $4.95 ; \mathrm{N}, 7.75 \%$.

Hexakis-(acetylamino-acetic acid-ethyl ester)-oxy triphenylene (2a): $1 \mathbf{a}(3.36 \mathrm{~g}, 15 \mathrm{mmol})$ was dissolved in DMF (10 mL, anhydrous) to which hexahydroxytriphenylene $(0.65 \mathrm{~g}, 2.0$ mmol) and powdered $\mathrm{K}_{2} \mathrm{CO}_{3}(4.98 \mathrm{~g}, 36.0 \mathrm{mmol})$ were added. The suspension was stirred under argon at room temperature for 5 days after which an excess of water was added and the resulting precipitate was collected by filtration and dried. The dry precipitate was purified by washing with water, and dissolving in $\mathrm{CHCl}_{3}$ and precipitation with an excess of petroleum ether. Pure 2a was recovered as a solid after evaporation of the remaining solvent and drying $(1.91 \mathrm{~g}, 1.62 \mathrm{mmol}, 81 \%)$ mp: 232-234 ${ }^{\circ} \mathrm{C} . \delta_{\mathrm{H}}\left(\mathrm{DMSO}-d_{6}\right) 1.23(\mathrm{t}$, $\left.18 \mathrm{H}, \mathrm{CH}_{3} \mathrm{CH}_{2} \mathrm{O}\right), 4.04\left(\mathrm{~d}, 12 \mathrm{H}, \mathrm{NHCH}_{2} \mathrm{C}=\mathrm{O}\right), 4.17\left(\mathrm{q}, 12 \mathrm{H}, \mathrm{CH}_{3} \mathrm{CH}_{2} \mathrm{O}\right), 4.95(\mathrm{~s}, 12 \mathrm{H}$, $\left.\mathrm{ArOCH}_{2}\right), 8.25(\mathrm{~s}, 6 \mathrm{H}, \mathrm{ArH}), 8.62\left(\mathrm{t}, 6 \mathrm{H}, \mathrm{O}=\mathrm{CNHCH}_{2}\right) . \delta_{\mathrm{C}}\left(\mathrm{DMSO}-d_{6}\right)$ 14.4, 39.8, 60.9, 68.7, 108.8, 124.0, 147.7, 168.8, 170.0. MS (ES): m/z 1205.4014, expect 1205.4026 for $[\mathrm{MNa}]^{+}$Anal. Calcd. for $\mathrm{C}_{54} \mathrm{H}_{66} \mathrm{~N}_{6} \mathrm{O}_{24}$ : C, 54.82; H, 5.62; N 7.10. Found: C, 54.73; H, $5.55 ; \mathrm{N}, 7.08 \%$. 
Hexakis-(2-acetylamino-acetic acid ethyl ester)-oxy triphenylene (2b): 1b (2.84 g, 12 mmol) was dissolved in DMF (10 $\mathrm{mL}$, anhydrous) to which hexahydroxytriphenylene ( $0.49 \mathrm{~g}, 1.5 \mathrm{mmol})$ and powdered $\mathrm{K}_{2} \mathrm{CO}_{3}(4.15 \mathrm{~g}, 30 \mathrm{mmol})$ were added. The suspension was stirred under argon at room temperature for 5 days after which an excess of water was added and the resulting precipitate was collected by filtration and dried. The dry precipitate was purified on a flash silica column $\left(1: 40 \mathrm{v} / \mathrm{v}\right.$ EtOAc/ $\left./ \mathrm{CHCl}_{3}\right)$ to give $\mathbf{2 b}$ as a light yellow solid $(1.25 \mathrm{~g}, 0.99 \mathrm{mmol}, 66 \%) .[\alpha]_{\mathrm{D}}=+9.5\left(\mathrm{c} 0.81, \mathrm{CHCl}_{3}\right)$; mp: $222-$ $223^{\circ} \mathrm{C}$.

$\delta_{\mathrm{H}}\left(\mathrm{CHCl}_{3}\right) 1.27\left(\mathrm{t}, 18 \mathrm{H}, \mathrm{CH}_{3} \mathrm{CH}_{2} \mathrm{O}\right), 1.52\left(\mathrm{~d}, 18 \mathrm{H}, \mathrm{CH}_{3} \mathrm{CHC}=\mathrm{O}\right), 4.20(\mathrm{q}, 12 \mathrm{H}$, $\left.\mathrm{CH}_{3} \mathrm{CH}_{2} \mathrm{O}\right), 4.72\left(\mathrm{~m}, 6 \mathrm{H}, \mathrm{NHCHCH}_{3}\right), 4.86\left(\mathrm{~s}, 12 \mathrm{H}, \mathrm{ArOCH}_{2}\right), 7.54(\mathrm{~d}, 6 \mathrm{H}, \mathrm{O}=\mathrm{CNHCH})$, $7.98(\mathrm{~s}, 6 \mathrm{H}, \mathrm{ArH}) . \delta_{\mathrm{C}}\left(\mathrm{CHCl}_{3}\right) 14.1,18.1,48.0,61.7,69.0,108.5,124.4,147.4,167.8$, 172.8. MS (ES): $\mathrm{m} / \mathrm{z}$ 1289.4803, expect 1289.4965 for $[\mathrm{MNa}]^{+}$. Anal. Calcd. for $\mathrm{C}_{60} \mathrm{H}_{78} \mathrm{~N}_{6} \mathrm{O}_{24}$ : C 56.86, H 6.20, N 6.63; Found: C 56.1, H 6.40, N 6.50\%.

L-Hexakis-(2-acetylamino-3-phenyl-propionic acid ethyl ester)-oxy triphenylene (2c): 2c was prepared using the same protocol as for 2a with the exception that 1c $(3.77 \mathrm{~g}, 12$ mmol) was used instead of $\mathbf{1 a}$, and the amounts of HAT-0 and $\mathrm{K}_{2} \mathrm{CO}_{3}$ were reduced to $0.49 \mathrm{~g}(1.5 \mathrm{mmol})$ and $4.15 \mathrm{~g}(30 \mathrm{mmol})$ respectively. The dry precipitate was purified on a flash silica column $\left(1: 4 \mathrm{v} / \mathrm{v}\right.$ EtOAc/ $\left./ \mathrm{CHCl}_{3}\right)$ to give $2 \mathrm{c}$ as a yellow solid $(1.86 \mathrm{~g}, 1.08$ mmol, $72 \%)$. mp: $155^{\circ} \mathrm{C} .[\alpha]_{\mathrm{D}}=+78\left(\mathrm{c} 0.95, \mathrm{CHCl}_{3}\right)$

$\delta_{\mathrm{H}}\left(\mathrm{CHCl}_{3}\right) \delta=1.21\left(\mathrm{t}, 18 \mathrm{H}, \mathrm{CH}_{3} \mathrm{CH}_{2} \mathrm{O}\right), 3.16\left(\mathrm{t}, 12 \mathrm{H}, \mathrm{CHCH}_{2} \mathrm{Ph}\right), 4.17\left(\mathrm{q}, 12 \mathrm{H}, \mathrm{CH}_{3} \mathrm{CH} \mathrm{O}\right)$, $4.69\left(\mathrm{q}, 12 \mathrm{H}, \mathrm{OCH}_{2} \mathrm{C}=\mathrm{O}\right), 4.96(\mathrm{q}, 6 \mathrm{H}, \mathrm{NHCHC}=\mathrm{O}), 7.04(\mathrm{~m}, 30 \mathrm{H}, \mathrm{PhH}), 7.41(\mathrm{~d}, 6 \mathrm{H}, N H)$, $7.84(\mathrm{~s}, 6 \mathrm{H}, \mathrm{ArH}) . \delta_{\mathrm{C}}\left(\mathrm{CHCl}_{3}\right) 14.1,37.9,53.0,61.7,69.7,109.5,124.8,127.0,128.5,129.2$, 135.8, 147.9, 168.1, 171.4. MS (ES): $\mathrm{m} / \mathrm{z}=1745.6859$, expect 1745.6843 for $[\mathrm{MNa}]^{+}$. Anal. Calcd. $\mathrm{C}_{96} \mathrm{H}_{102} \mathrm{~N}_{6} \mathrm{O}_{24}$ : C 66.88, H 5.96, N 4.88; Found: C 66.6, H 5.90, N 4.80\%.

L-Hexakis-(2-acetylamino-3-(1H-indol-3-yl)-propionic acid ethyl ester)-oxy triphenylene $(\mathbf{2 d}): \mathbf{2 d}$ was prepared using the same protocol as for $\mathbf{2 a}$ with the exception that $1 \mathbf{1 c}(2.12$ $\mathrm{g}, 6 \mathrm{mmol}$ ) was used instead of $\mathbf{1 a}$, and the amounts of HAT-0 and $\mathrm{K}_{2} \mathrm{CO}_{3}$ were reduced to $0.26 \mathrm{~g}(0.75 \mathrm{mmol})$ and $2.77 \mathrm{~g}(20 \mathrm{mmol})$ respectively. The dry precipitate was purified by using flash chromatography $\left(1: 4 \mathrm{EtOAc} / \mathrm{CHCl}_{3} \mathrm{v} / \mathrm{v}\right)$ to give $2 \mathrm{c}$ as a yellow/grey solid $(0.98 \mathrm{~g}, 0.50 \mathrm{mmol}, 67 \%) \mathrm{mp}: 120^{\circ} \mathrm{C}$. $[\alpha]_{\mathrm{D}}=+90.6\left(\mathrm{c} 0.98, \mathrm{CHCl}_{3}\right)$ $\delta_{\mathrm{H}}\left(500 \mathrm{MHz}, \mathrm{CDCl}_{3}\right) 1.24\left(\mathrm{t}, 18 \mathrm{H}, \mathrm{CH}_{3} \mathrm{CH}_{2} \mathrm{O}\right), 3.36\left(\mathrm{~m}, 12 \mathrm{H}, \mathrm{CHCH}_{2} \mathrm{Ar}\right), 4.15(\mathrm{q}, 12 \mathrm{H}$, $\left.\mathrm{CH}_{3} \mathrm{CH}_{2} \mathrm{O}\right), 4.55\left(\mathrm{~s}, 12 \mathrm{H}, \operatorname{ArOCH}_{2} \mathrm{C}=\mathrm{O}\right), 4.88\left(\mathrm{~m}, 6 \mathrm{H}, \mathrm{NHCH}\left(\mathrm{CH}_{2}\right) \mathrm{C}=\mathrm{O}\right), 7.1(\mathrm{~d}, 6 \mathrm{H}$, $\mathrm{O}=\mathrm{CNHCH} 2), 7.0-7.65(\mathrm{~m}, 6 \mathrm{H}, \mathrm{Ar} H) . \delta_{\mathrm{C}}\left(\mathrm{CDCl}_{3}\right)$ 14.1, 26.9, 51.8, 62.1, 68.6, 107.9, $108.6,111.5,118.0,119.3,122.1,122.9,124.1,127.1,136.3,146.7,168.5,172.4$. MS (ES): $\mathrm{m} / \mathrm{z}=1979.7530$, expect 1979.7497 for $[\mathrm{M}+\mathrm{Na}]^{+}$. Anal. Calcd. for $\mathrm{C}_{108} \mathrm{H}_{108} \mathrm{O}_{24} \mathrm{~N}_{12} .3 \mathrm{H}_{2} \mathrm{O}$ : C, 64.46; H, 5.71; N, 8.36. Found: C 64.6; H 5.6; N 8.2\%.

\section{Results and Discussion}

The synthesis of the $t$-butyl derivative of $\mathbf{2 a}$ has previously been reported by Bechgaard et al. ${ }^{33}$, in four steps starting from HAT-0. When we attempted to use a similar procedure to generate the ethyl derivative $\mathbf{2 a}$, we experienced difficulties in isolating a pure product 
from the second step. Hence the reaction scheme in Fig. 1 was designed, where the presynthesised side-chain bromoacetyl amino acid ethyl ester is coupled to HAT-0 in a single step. In our hands, this route gave pure products (after crystallisation or flash chromatography) in acceptable yields, both for $\mathbf{2 a}$ and for the other amino acid variants. Bromoacetyl amino acid ethyl esters have been prepared by different routes: the method of Lipowska ${ }^{35}$ et al. using dichloromethane as solvent and triethylamine as base was found to be most successful, although the intermediates were usually obtained as intractable mixtures of bromo- and chloro-derivatives. These however reacted completely with hexahydroxy triphenylene and the general route in Fig. 1 was successfully used to synthesise novel compounds $\mathbf{2 a - 2 d}$.

The solubility and gelation results for $\mathbf{2 a - 2 d}$ are summarised in Table 1. 2a was found to be capable of gelating chloroform and dichloromethane at relatively low concentrations. Samples containing as little as $2-10 \mathrm{mg} \mathrm{mL}^{-1}$ in chloroform or $0.5-2 \mathrm{mg} \mathrm{mL}^{-1}$ in DCM exhibited clots of gelled solvent although they were not completely gelled throughout (Table 2). These compare favorably with the lowest reported critical gel concentrations for other triphenylene derivative organogelators ${ }^{17,18,20,22}$. High concentrations of 2 a (10 $\mathrm{mg} / \mathrm{ml}$ in chloroform, $2 \mathrm{mg} \mathrm{mL}^{-1}$ in DCM)) led to the formation of self supporting opaque gels (Fig. 2), SEM examination of these gels showed them to be composed of thick ( $>$ $200 \mathrm{~nm}$ wide) tendril-like organogel fibres (Fig. 3a).

Table 1. Solubility study results.

\begin{tabular}{ccccc}
\hline & $\mathbf{2 a}$ & $\mathbf{2 b}$ & $\mathbf{2 c}$ & $\mathbf{2 d}$ \\
\hline $\mathrm{H}_{2} \mathrm{O}$ & $\mathrm{I}$ & $\mathrm{I}$ & $\mathrm{I}$ & $\mathrm{I}$ \\
$\mathrm{MeOH}$ & $\mathrm{I}$ & $200^{\mathrm{H}}, \mathrm{P}^{\mathrm{C}}$ & 800 & 600 \\
$\mathrm{EtOH}$ & $\mathrm{I}$ & $200^{\mathrm{H}}, \mathrm{G}^{\mathrm{C}}$ & 1000 & 800 \\
$\mathrm{THF}$ & $\mathrm{I}$ & $100^{\mathrm{H}}, \mathrm{P}^{\mathrm{C}}$ & 400 & 400 \\
$\mathrm{DCM}$ & $200^{\mathrm{H}}, \mathrm{G}^{\mathrm{C}}$ & 50 & 50 & 50 \\
$\mathrm{CHCl}_{3}$ & $200^{\mathrm{H}}, \mathrm{G}^{\mathrm{C}}$ & 50 & 50 & 400 \\
$\mathrm{DMSO}$ & 300 & 50 & 50 & 50 \\
$\mathrm{DMF}$ & 400 & 50 & 50 & 50 \\
MeCN & $200, \mathrm{P}^{\mathrm{C}}$ & $100^{\mathrm{H}}, \mathrm{P}^{\mathrm{C}}$ & $200, \mathrm{P}^{\mathrm{C}}$ & 200 \\
Benzene & $\mathrm{I}$ & $200^{\mathrm{H}}, \mathrm{P}^{\mathrm{C}}$ & $200^{\mathrm{H}}, \mathrm{G}^{\mathrm{C}}$ & 200 \\
Toluene & $\mathrm{I}$ & $200^{\mathrm{H}}, \mathrm{G}^{\mathrm{C}}$ & $200^{\mathrm{H}}, \mathrm{G}^{\mathrm{C}}$ & $200^{\mathrm{H}}, \mathrm{P}^{\mathrm{C}}$ \\
\hline
\end{tabular}

Numbers indicate volume of solvent $(\mu \mathrm{L})$ needed to solubilise $10 \mathrm{mg}$ sample at room temperature after heating on an oil bath to $120^{\circ} \mathrm{C}$ or to the solvent's boiling temperature (whichever is lowest) and cooling to room temperature for $1 \mathrm{~h}$. I: insoluble (doesn't dissolve even in $10 \mathrm{~mL}$ ); P: precipitate; G: gel; H: on heating; C: cooling down. For example: $200^{\mathrm{H}}$ means $10 \mathrm{mg}$ sample are completely dissolved in $200 \mu \mathrm{L}$ solvent on heating, however it precipitates out when cooling down to room temperature $\left(\mathrm{P}^{\mathrm{C}}\right)$ or forms a gel when cooling down to room temperature $\left(\mathrm{G}^{\mathrm{C}}\right)$.

Table 2. Gel concentration results. 


\begin{tabular}{ccc}
\hline & $\begin{array}{c}\text { Min. concn. for loose/partial } \\
\text { gel } / \mathrm{mg} \mathrm{mL}^{-1}\end{array}$ & $\begin{array}{c}\text { Min. concn. for full gel } \\
\text { (self-supporting) } / \mathrm{mg} \mathrm{mL}^{-1}\end{array}$ \\
\hline 2a in $\mathrm{CHCl}_{3}$ & 2 & 10 \\
2a in $\mathrm{CH}_{2} \mathrm{Cl}_{2}$ & $<0.5$ & 2 \\
2b in toluene & 0.5 & 40 \\
2b in $\mathrm{EtOH}$ & 2 & 25 \\
2c in toluene & 1 & 15 \\
2c in benzene & 2 & 30
\end{tabular}

Samples at different concentrations were heated to the solvent's boiling temperature then cooled to RT.

Interestingly whilst $\mathbf{2 b}$ and $\mathbf{2 c}$ did not gel chloroform or DCM, they were both capable of gelling toluene (Fig. 2, 3b and 3c), whilst 2a could not even be dissolved in toluene on heating. These gels when examined under the SEM comprised narrower fibres, of 50-100 $\mathrm{nm}$ diameter (Fig. 3b-c). 2 b also gelled ethanol, at relatively high concentrations, and this gel comprised even narrower fibres of $20-50 \mathrm{~nm}$ diameter (Fig. 3d). 2c was also able to gel benzene. Other aromatic solvents were investigated but the derivatives all exhibited limited solubility.

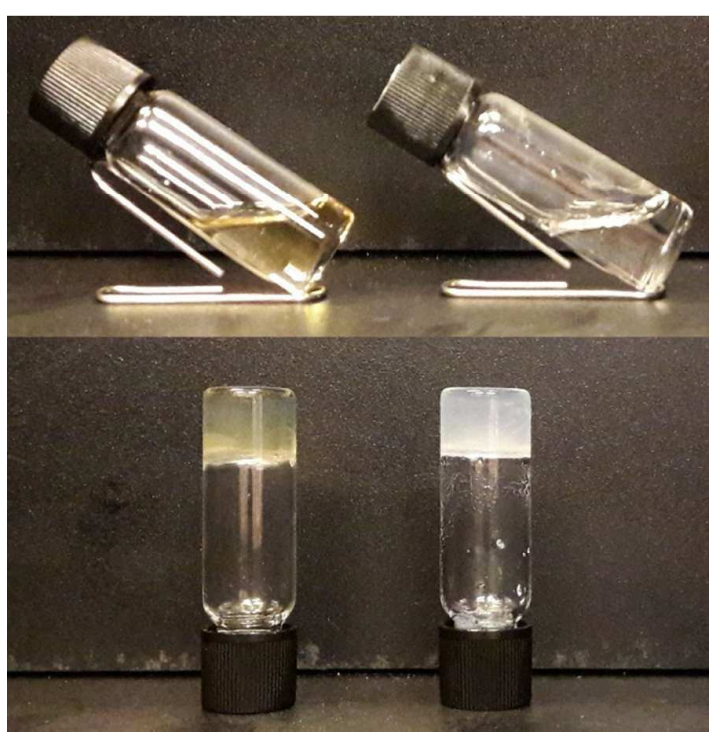

Figure 2. Photographs of the heated sols (top), and the gels formed at room temperature (bottom), from $10 \mathrm{mg} \mathrm{mL}^{-1} \mathbf{2} \mathbf{a}$ in chloroform (left) and $20 \mathrm{mg} \mathrm{mL}^{-1} \mathbf{2 b}$ in toluene (right).

2d was found to be soluble in all of the solvents studied with the exception of water and incapable of gelating any of them. Optical microscopy studies of 2d solutions $(\mathrm{MeOH}$, EtOH, THF, DCM, $1 \mathrm{mg} \mathrm{mL}^{-1} \mathbf{2 d}$ ) dispersed on glass slides showed however that $\mathbf{2 d}$ was completely dissolved in the solution, up until sufficient solvent had been removed by evaporation into the atmosphere to cause the formation of $\mathbf{2 d}$ microspheres of $\sim 1 \mu \mathrm{m}$. These can be seen by optical microscopy (Fig. 4) along with slightly larger aggregates. Although organogelators have been observed forming spherical micelles or spherulites on the nanoscale, there are only a few published examples of the formation of such regular microspheres by evaporation-induced self-assembly of low molecular weight organic molecules ${ }^{41}$, and the process is not well understood. The regular arrangement of the 
triphenylene microspheres is suggestive of photonic crystals, for example. The properties of the $\mathbf{2 d}$ microspheres and their self-assembly are the subject of ongoing research.
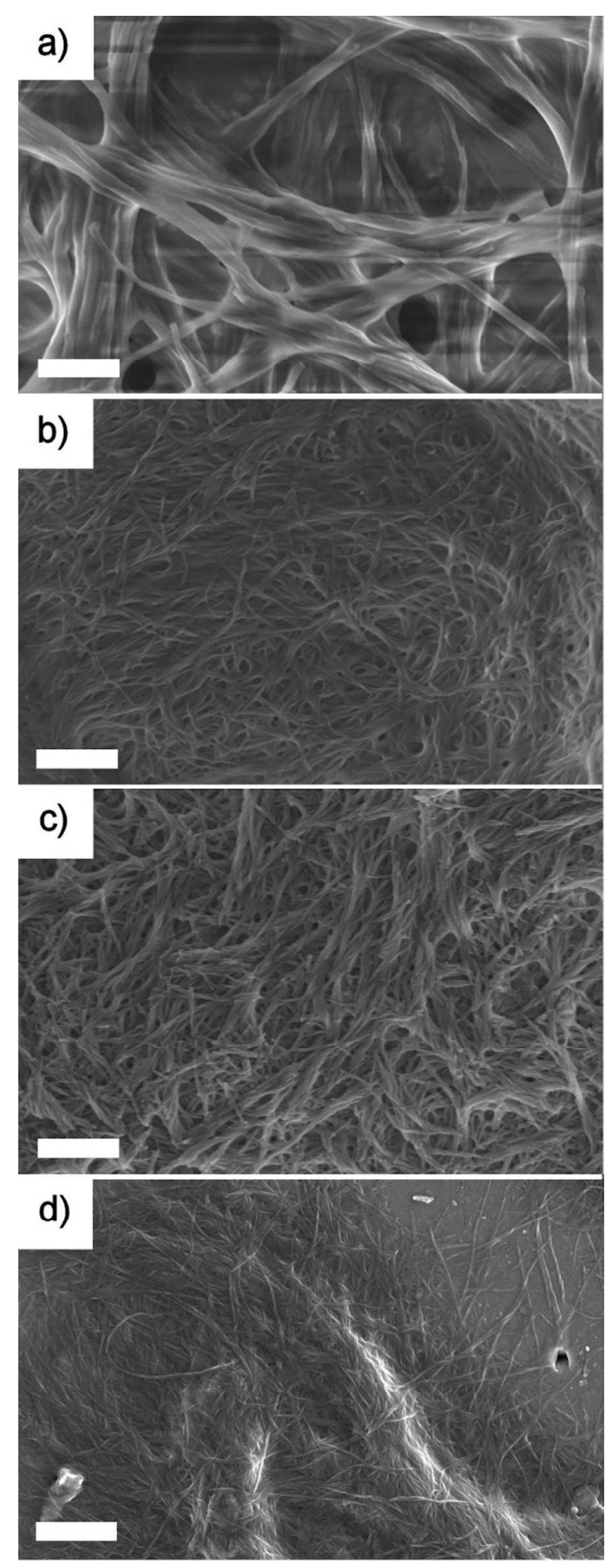

Figure 3. SEM images of xerogels formed by drying organogels of a) $\mathbf{2 a}\left(10 \mathrm{mg} \mathrm{mL}^{-1}\right)$ in chloroform, b) $\mathbf{2 b}\left(20 \mathrm{mg} \mathrm{mL}^{-1}\right)$ in toluene, c) $\mathbf{2 c}\left(20 \mathrm{mg} \mathrm{mL}^{-1}\right)$ in toluene, d) $\mathbf{2 b}(25 \mathrm{mg}$ $\mathrm{mL}^{-1}$ ) in EtOH. Original magnification in each case $\times 50,000$. Scale bar (bottom left) is 1 $\mu \mathrm{m}$. 


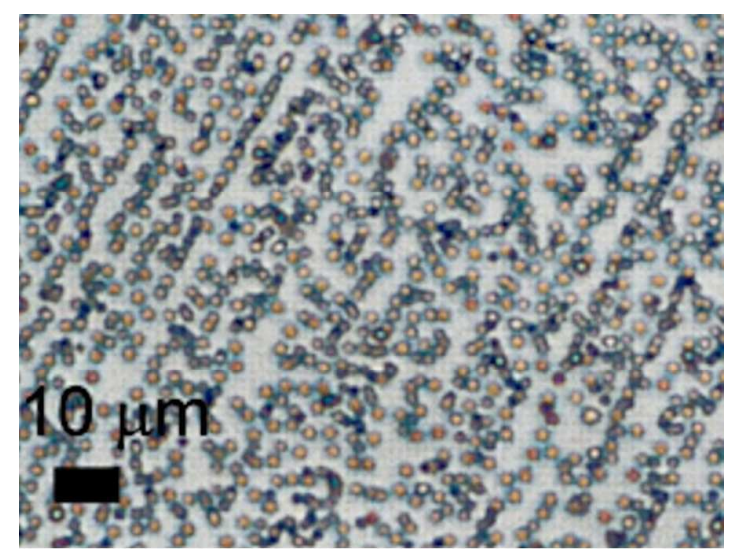

Figure 4. Optical micrograph of $\mathbf{2 d}$ microspheres, Scale bar $=10 \mu \mathrm{m}$.

The ability of LMOGs to gel different solvents is a complicated balance between the strength of gelator-gelator (solute-solute) interactions and solute-solvent interactions. Although some progress has been made in correlating the gelating ability of particular LMOGs with solvent parameters ${ }^{42}$, there is no rule set which can be universally applied. In the case of $\mathbf{2 a}-\mathbf{2 d}$, it is clear that $\mathbf{2 a}$ has lower solubility, in general, than the other triphenylene derivatives, indicating that $\mathbf{2 a - 2 a}$ interactions are, relatively, stronger than $\mathbf{2 b - 2 b}$ for example. Interestingly, all of the combinations that give rise to gels occur when the maximum solubility of the triphenylene derivative in hot solvent is about $50 \mathrm{mg} \mathrm{mL}^{-1}$ $(\sim 50 \mathrm{mM})$. This may indicate the optimum balance of solvent-solute vs. solute-solute interactions. Thus $\mathbf{2 b}$ dissolves in hot EtOH at $50 \mathrm{mg} \mathrm{mL}^{-1}$ and cools to give a gel: the other triphenylene derivatives are less soluble in EtOH and do not form gels, perhaps indicating the solute-solute interactions in these cases are too strong. 2a dissolves in hot $\mathrm{CHCl}_{3}$ or DCM at $50 \mathrm{mg} \mathrm{mL}$, and cools to form a gel, while $\mathbf{2 b - 2 d}$ are too soluble in these solvents (solute-solvent interactions are too strong) - except $\mathbf{2 d}$ in $\mathrm{CHCl}_{3}$ where the solubility is too low. $\mathbf{2 b}$ and $\mathbf{2 c}$ dissolve in hot toluene at $50 \mathrm{mg} \mathrm{mL}^{-1}$ and cool to give gels: $\mathbf{2 a}$ is too insoluble, and $\mathbf{2 d}$ precipitates rather than forming a gel, perhaps because the indole side chains sterically hinder 1D aggregation. There are other exceptions for example 2a, 2c and 2d dissolve in hot $\mathrm{MeCN}$ at about $50 \mathrm{mg} \mathrm{mL}^{-1}$ yet none form gels: perhaps because the polar aprotic solvents solvate the amide group particularly effectively.

The self-assembly behaviours of the triphenylenes were further investigated by ${ }^{1} \mathrm{H}$ NMR and some chemical shift/concentration plots are shown in Figure 5a. For 2a in $\mathrm{CDCl}_{3}$ the protons on and directly adjacent to the triphenylene core $\left(\mathrm{H}_{\mathrm{A}}\right.$ and $\left.\mathrm{H}_{\mathrm{B}}\right)$ undergo an increase in shielding as the concentration of 2a increases; however the protons associated with the amino acid side-chain $\left(\mathrm{H}_{\mathrm{D}}, \mathrm{H}_{\mathrm{E}}\right.$ and $\left.\mathrm{H}_{\mathrm{F}}\right)$ appear to exhibit a slight decrease in shielding. It is suggested that these changes are attributable to individual $2 \mathbf{2 a}$ monomers forming one dimensional aggregates in solution: as the triphenylene cores stack the ring protons $\left(\mathrm{H}_{\mathrm{A}}\right.$ and $\left.\mathrm{H}_{\mathrm{B}}\right)$ are shielded by the $\pi$ electron clouds of the triphenylene ring systems directly above and below them; the deshielding of the sidechain protons $\left(\mathrm{H}_{\mathrm{D}}, \mathrm{H}_{\mathrm{E}}\right.$ and $\left.\mathrm{H}_{\mathrm{F}}\right)$ may be caused by the side-chains being forced out into the plane of the triphenylene aromatic system and away from the shielding region generated 
by the aromatic ring current ${ }^{43}$, or simply by the influence of hydrogen bonds forming between side-chains.
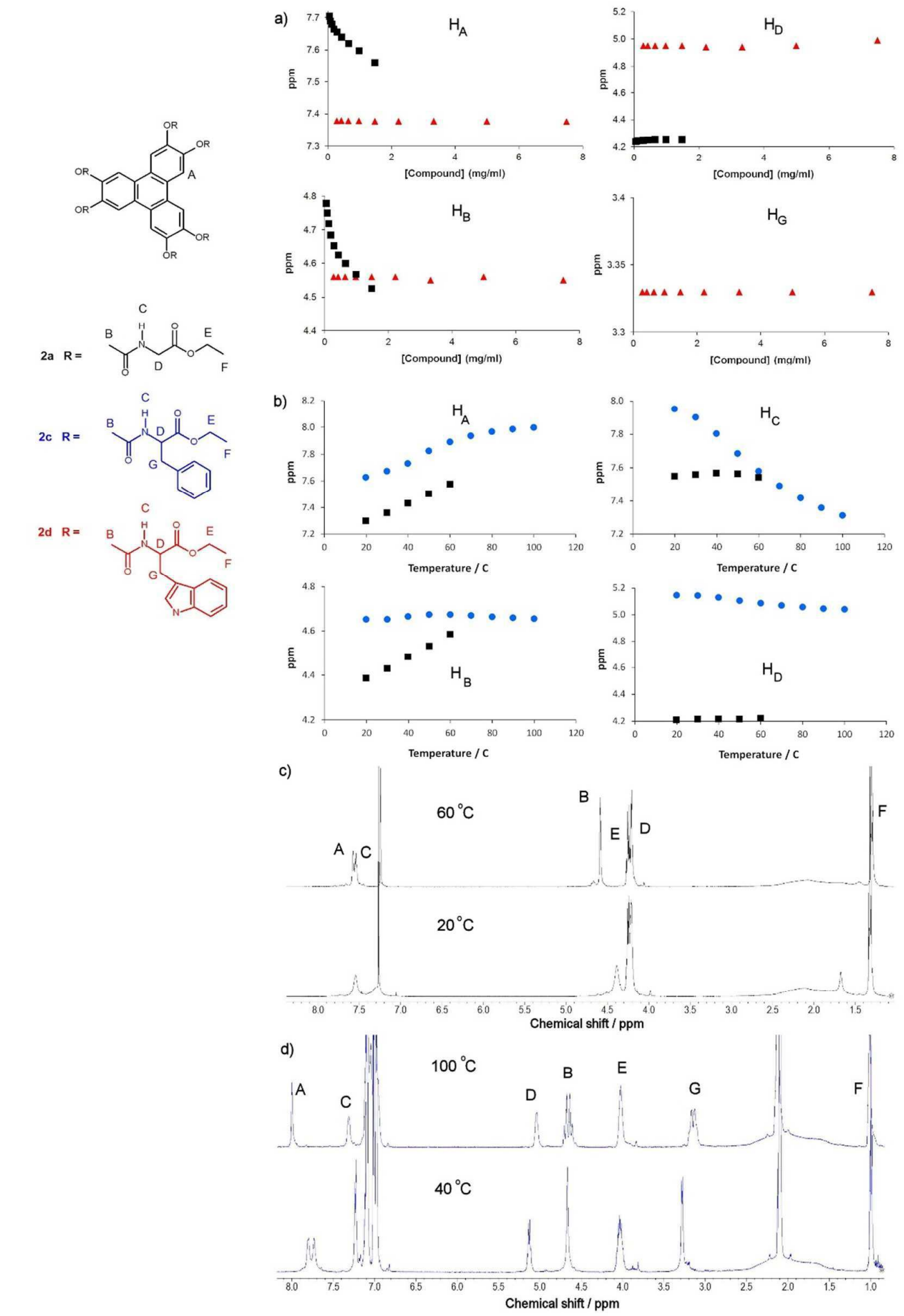

Figure 5. a) Concentration dependant ${ }^{1} \mathrm{H}$ NMR study of $\mathbf{2 a}$ and $\mathbf{2 d}$ in $\mathrm{CDCl}_{3}$. b) Temperature dependent ${ }^{1} \mathrm{H}$ NMR study of $\mathbf{2 a}$ in $\mathrm{CDCl}_{3}$ and $\mathbf{2 c}$ in $d_{8}$-toluene. c) Corresponding spectra for $\mathbf{2 a}$ in $\mathrm{CDCl}_{3}$ at different temperatures. d) Corresponding 
spectra for $\mathbf{2 c}$ in $d_{8}$-toluene at different temperatures. Black symbols correspond to $\mathbf{2 a}$, blue to $\mathbf{2 c}$ and red to $\mathbf{2 d}$ throughout.

In the case of $\mathbf{2} \mathbf{b}, \mathbf{2} \mathbf{c}$ and $\mathbf{2 d}$ in $\mathrm{CDCl}_{3}$ the chemical shifts of all the studied protons remain more or less constant, implying that the protons remain in a similar chemical environment over the concentration range studied (data for $\mathbf{2 d}$ are shown in Fig 5a).

Since the gels are thermoreversible, variable-temperature ${ }^{1} \mathrm{H}-\mathrm{NMR}$ was also conducted (Fig. 5b). For $2 \mathrm{a}$ in $\mathrm{CDCl}_{3}, \mathrm{H}_{\mathrm{A}}$ and $\mathrm{H}_{\mathrm{B}}$ become progressively more deshielded as the temperature increases, corresponding to aggregates dissociating and the triphenylenes reverting to the monomeric state, in agreement with the concentration-dependent results (Fig. 5c). For 2c in $d_{8}$-toluene, $\mathrm{H}_{\mathrm{A}}$ becomes more deshielded with increasing temperature, suggesting the aromatic protons are again more shielded in the aggregated state. However, the change in chemical shift for $\mathrm{H}_{\mathrm{B}}$ with increasing temperature is minimal, whilst the amide proton $\mathrm{H}_{\mathrm{C}}$ is progressively more shielded with increasing temperature (for $\mathbf{2 a}, \mathrm{H}_{\mathrm{C}}$ barely changes with temperature). Other nuclei including $\mathrm{H}_{\mathrm{D}}, \mathrm{H}_{\mathrm{G}}$ and the phenyl protons also demonstrated changes in shift with temperature for $2 \mathbf{c}$ in $d_{8}$-toluene and there were quite dramatic changes in lineshape: e.g. $\mathrm{H}_{\mathrm{B}}$ of $\mathbf{2 c}$ in $d_{8}$-toluene is a singlet at low temperature as might be expected, but splits into two strongly coupled doublets at high temperature (Fig. 5d). These observations suggest the mode of aggregation of $2 \mathrm{c}$ in $d_{8}$-toluene may be significantly different from that of $\mathbf{2 a}$ in $\mathrm{CDCl}_{3}$, with the amide group implicated in aggregation perhaps via hydrogen-bonding and the phenyl group involved via $\pi-\pi$ interactions. At high temperature (in the non-aggregated state) the two $\mathrm{H}_{\mathrm{B}}$ protons become non-equivalent, indicating that there is some preferred conformation of the sidechains in which the symmetry of these protons is lost: on aggregation, the side-chains may be forced into a different conformation where the $\mathrm{H}_{\mathrm{B}}$ protons become equivalent again.

The absorbance and emission properties of $\mathbf{2 a - d}$ were studied in different solvents. Figure 6 shows the spectra of $\mathbf{2 a}$ in $\mathrm{MeCN}$ (a non-gelling solvent) and in $\mathrm{CHCl}_{3}$ (a gelling solvent), and of $\mathbf{2 b}$ in $\mathrm{MeCN}$ (a non-gelling solvent) and toluene (a gelling solvent). The absorption spectra (Fig. 6a) appear similar in each case, with a maximum about $277 \mathrm{~nm}$ (although this is harder to discern in toluene due to the background absorption), and are quite similar to those of HAT-5 in heptane described by Markovitski et al. ${ }^{44}$ and of the poly(ethoxylated) triphenylene TP6EO2M in dichloromethane ${ }^{14}$. By analogy with Markovitsi the main peak can be assigned to the $\mathrm{S}_{0}-\mathrm{S}_{4}$ transition. When 2a is measured in the gelling solvent $\mathrm{CHCl}_{3}$, its absorbance is very slightly higher than in non-gelling $\mathrm{MeCN}$, but there is little change in $\lambda_{\max }$. Similarly, when spectra are recorded for $\mathbf{2 a}$ at increasing concentration in $\mathrm{CHCl}_{3}$ there is little change in the shape of the spectrum (see supplementary information Figure S9). By contrast, the spectrum of $\mathbf{2 b}$ in toluene (a gelling solvent) is different from that in $\mathrm{MeCN}$, in particular the shoulder at $320 \mathrm{~nm}$ (due to the $\mathrm{S}_{0}-\mathrm{S}_{3}$ transition) shows lower absorbance. Absorbance spectroscopy studies of other organogelating triphenylene derivatives have been inconclusive: Shinkai et al. compared their triphenylene derivatives in $\mathrm{CHCl}_{3}$ (a non-gelling solvent) and in cyclohexane (a gelling solvent) and observed a significant blue shift ${ }^{45}$, but Kimura et al. 
compared their derivatives in methoxyethanol (a gelling solvent) above and below the gel temperature and saw little change ${ }^{26}$.

In $\mathrm{MeCN}$ (non-gelling) the emission spectra (Fig. 6b) of all compounds are similar, with $\lambda_{\max }$ at $379 \mathrm{~nm}$ and shoulders at 367 and $397 \mathrm{~nm}$. 2b shows higher fluorescence than 2a. Moving from non-gelling $\mathrm{MeCN}$ to gelling $\mathrm{CHCl}_{3}$, the emission from 2a shows little change in intensity but is slightly red-shifted $\left(\lambda_{\max }=381 \mathrm{~nm}\right)$. Similarly, when spectra are recorded for $\mathbf{2 a}$ in $\mathrm{CHCl}_{3}$ at increasing concentrations $\left(1.0 \mu \mathrm{g} \mathrm{mL}^{-1}\right.$ to $\left.1.0 \mathrm{mg} \mathrm{mL}^{-1}\right), \lambda_{\max }$ shifts from 379 to $384 \mathrm{~nm}$ (see supplementary information Figure S9). These results are consistent with observations on organogelating triphenylenes by Bai et al. ${ }^{21}$, Kimura et $a l{ }^{26}$ and Munoz Resta et $a l .^{25}$, but again contrast with those of Shinkai et al. ${ }^{45}$ who observed emission spectra similar to Fig. $6 \mathrm{~b}$ for their triphenylene derivative in chloroform (no gel) but a large new emission peak above $500 \mathrm{~nm}$, attributed to excimer emission, for their triphenylene in cyclohexane (gel). Moving from $\mathrm{MeCN}$ (non-gelling) to toluene (gelling), the emission of $\mathbf{2 b}$ is also red shifted $\left(\lambda_{\max }=383 \mathrm{~nm}\right)$, broadens and falls, though the latter may be due to the reduced absorbance observed for $\mathbf{2 b}$ in toluene at the excitation wavelength of $320 \mathrm{~nm}$.

Shinkai et al. explained the dramatic changes in fluorescence observed for their organogelating triphenylene by proposing the compound was able to adopt an eclipsed configuration in the aggregated state, which stabilised the excimer ${ }^{17}$. Most triphenylenes aggregate in staggered conformations and exhibit smaller changes in their fluorescence behaviour, as observed here for 2a-2c. Our resuts are consistent with the case of TP6EO2M in $\mathrm{D}_{2} \mathrm{O}$, where the emission peak does not change shape and shifts by just $7 \mathrm{~nm}$ over three decades of concentration ${ }^{14}$, and with other works cited above. The columnar organisation of TP6EO2M in $\mathrm{D}_{2} \mathrm{O}$ is supported by X-ray and other evidence and is not disputed. Moreover, the concentrations studied here are below the gel concentrations reported in Table 2. Thus, the small changes in fluorescence wavelength for $\mathbf{2 a}$ in $\mathrm{CHCl}_{3}$, and for $\mathbf{2 b}$ and $\mathbf{2 c}$ in toluene, are consistent with $\pi-\pi$ interactions and columnar aggregation in the corresponding organogels. 

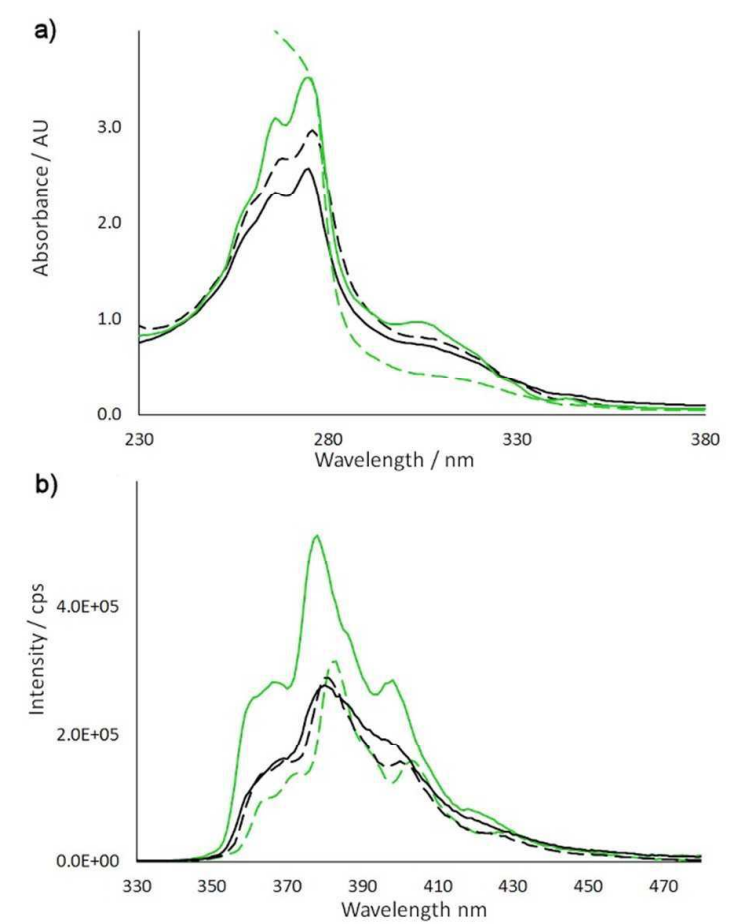

Figure 6. a) UV absorbance, and b) fluorescence emission $\left(\lambda_{\mathrm{ex}}=320 \mathrm{~nm}\right)$ spectra of 0.5 $\mathrm{mM} 2 \mathrm{a}$ in MeCN (black, solid line) and in chloroform (black dashed line), and of $0.5 \mathrm{mM}$ $\mathbf{2 b}$ in $\mathrm{MeCN}$ (green solid line) and in toluene (green dashed line).

Infrared spectroscopy provides a further tool for studying the assembly of organogelators. Previous published studies have compared FTIR spectra of gelators in different solvents, corresponding to the gel and solution state ${ }^{19,25,46}$. Spectra for $2 \mathbf{c}$ in DCM (solution) and toluene (gel) are compared in figure 7 . The carbonyl stretching bands move noticeably: the ester band from 1733 to $1738 \mathrm{~cm}^{-1}$ and the amide I band from 1683 to $1669 \mathrm{~cm}^{-1}$. A similar shift for the amide I band was observed by Tao et al. ${ }^{19}$ when they compared their triphenylene amine gelator in DMF solution and p-xylene gel state, and such a change is characteristic of increased hydrogen bonding ${ }^{46}$. Furthermore the $-\mathrm{NH}$ stretch changes dramatically: the signal at $3410 \mathrm{~cm}^{-1}$ in DCM, moves to $3301 \mathrm{~cm}^{-1}$ in toluene, again similarly to the change observed by Tao et al. when comparing the solution and gel state.

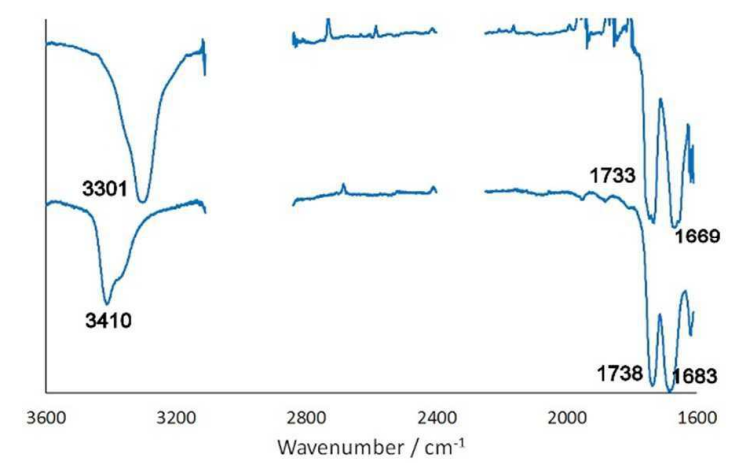

Figure 7. FTIR spectra for $20 \mathrm{mg} \mathrm{mL}^{-1} \mathbf{2 c}$ in toluene (gel, top) and in DCM (solution, bottom). Regions of the spectra subject to noise due to the high absorbance of the solvent have been deleted. 
To provide further information on the molecular organisation of the triphenylenes, dried xerogel formed from 2a organogel in $\mathrm{CHCl}_{3}$ was subjected to powder X-ray diffraction (Fig. 8). The scattering pattern shows broad peaks in the wide angle range corresponding to spacings of about $0.35 \mathrm{~nm}$ and $0.42 \mathrm{~nm}$, closely analogous to equivalent patterns for xerogels derived from other triphenylene organogels, in which these peaks have been attributed to the face-to-face distance between discs ${ }^{17,20,24,25,26}$ and to scattering from disordered side-chains ${ }^{17,24,25}$, as well as one corresponding to $\mathrm{d}=0.71 \mathrm{~nm}$, which is hard to assign but would correspond to alternate stacked $\pi$-systems. Other studies on xerogels from dried triphenylene derivative organogels have observed one or two sharper peaks in the small angle regime, corresponding to spacings from 1.7 to $5.1 \mathrm{~nm}$, which have been attributed to the spacing between columns ${ }^{17,20,24,25}$. Where more than one peak is visible, columnar hexagonal, rectangular or oblique structures have tentatively been assigned ${ }^{17,25}$. In Figure 8 three small angle peaks are observed corresponding to spacings of 2.93, 1.90 and $1.57 \mathrm{~nm}$. These do not fit the pattern expected for a columnar hexagonal structure, but do fit a columnar rectangular, or columnar oblique structure such has been observed also for example in some pure thermotropic triphenylene derivatives ${ }^{47}$.

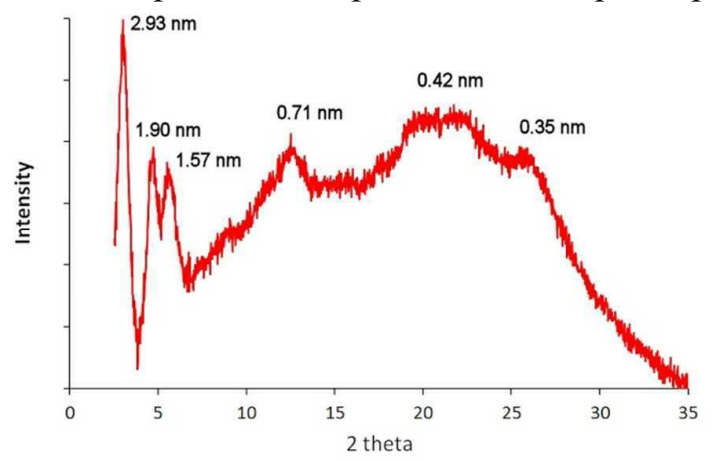

Figure 8. X-ray scattering pattern for powdered xerogel from dried gel of $\mathbf{2 a}$ in $\mathrm{CHCl}_{3}$.

The structure of a dried xerogel does not necessarily correspond to the original organogel, but measurements on wet gels are challenging and rarely reported: there is only one example of WAXS on an organogelating triphenylene in the wet gel state, in which broad, noisy diffractions corresponding to spacings of about $0.45,1.4$ and $2.5 \mathrm{~nm}$ were observed and no particular inter-columnar organization was assigned ${ }^{22}$. We undertook SAXS studies of the wet gels of $\mathbf{2 a}$ in $\mathrm{CHCl}_{3}, \mathbf{2 b}$ and $\mathbf{2} \mathbf{c}$ in toluene (Fig. 9). The highest packing order was found for $\mathbf{2 a}$ in $\mathrm{CHCl}_{3}$ (panel a). The three peaks assigned 10, 01 and 11 correspond to d-spacings of 2.94, 1.94 and $1.57 \mathrm{~nm}$, in good agreement with the pattern for the dried xerogel. They can be fitted to a monoclinic lattice with $a=2.94 \mathrm{~nm}, b=1.94$ $\mathrm{nm}$ and $\gamma=94^{\circ}$, corresponding to a columnar oblique $\left(\mathrm{Col}_{\mathrm{o}}\right)$ structure overall. At high temperature $\left(65{ }^{\circ} \mathrm{C}\right)$, an additional diffraction peak can be seen around $\mathrm{q}=1.2 \mathrm{~nm}^{-1}$ that vanishes when the sample is cooled down to $25{ }^{\circ} \mathrm{C}$. The origin of this diffraction peak remains unclear, but it might arise from a temporarily coexisting superlattice as observed by $\mathrm{Mu}$ et $a l .{ }^{47}$ in liquid crystalline triphenylene polymers.

It is important to note that the thickness of the fibres observed by SEM $(20-200 \mathrm{~nm})$ is much greater than the separation between columns of molecules (order $2 \mathrm{~nm}$ ) revealed by the SAX studies and so each fibre must be composed of a 'bundle' of molecular columns. 
The fact that the dispersity in thickness of the fibres varies little within any given sample (Fig. 3) further suggests that there is some factor which controls and limits the sideways growth of these fibres.

2c in toluene (Fig. 9b) by contrast shows a less ordered structure. We note, that clearly the first two diffraction orders are seen. A straightforward interpretation could be that each column is only coupled to two nearest neighbours, leading to stable layers of columns with a thickness of $2.1 \mathrm{~nm}$. However, adjacent layers are not in registry otherwise additional diffraction peaks indicating a 2D-lattice would be observed. In the third sample of $\mathbf{2 b}$ in toluene an even weaker coupling between the columns is evident. Only a very broad first order diffraction peak evidences a highly disordered layering of the columns with a d-spacing of about $1.9 \mathrm{~nm}$. The closer spacing observed with $\mathbf{2 b}$ compared to $\mathbf{2 c}$ is consistent with the less bulky nature of the side-chains.
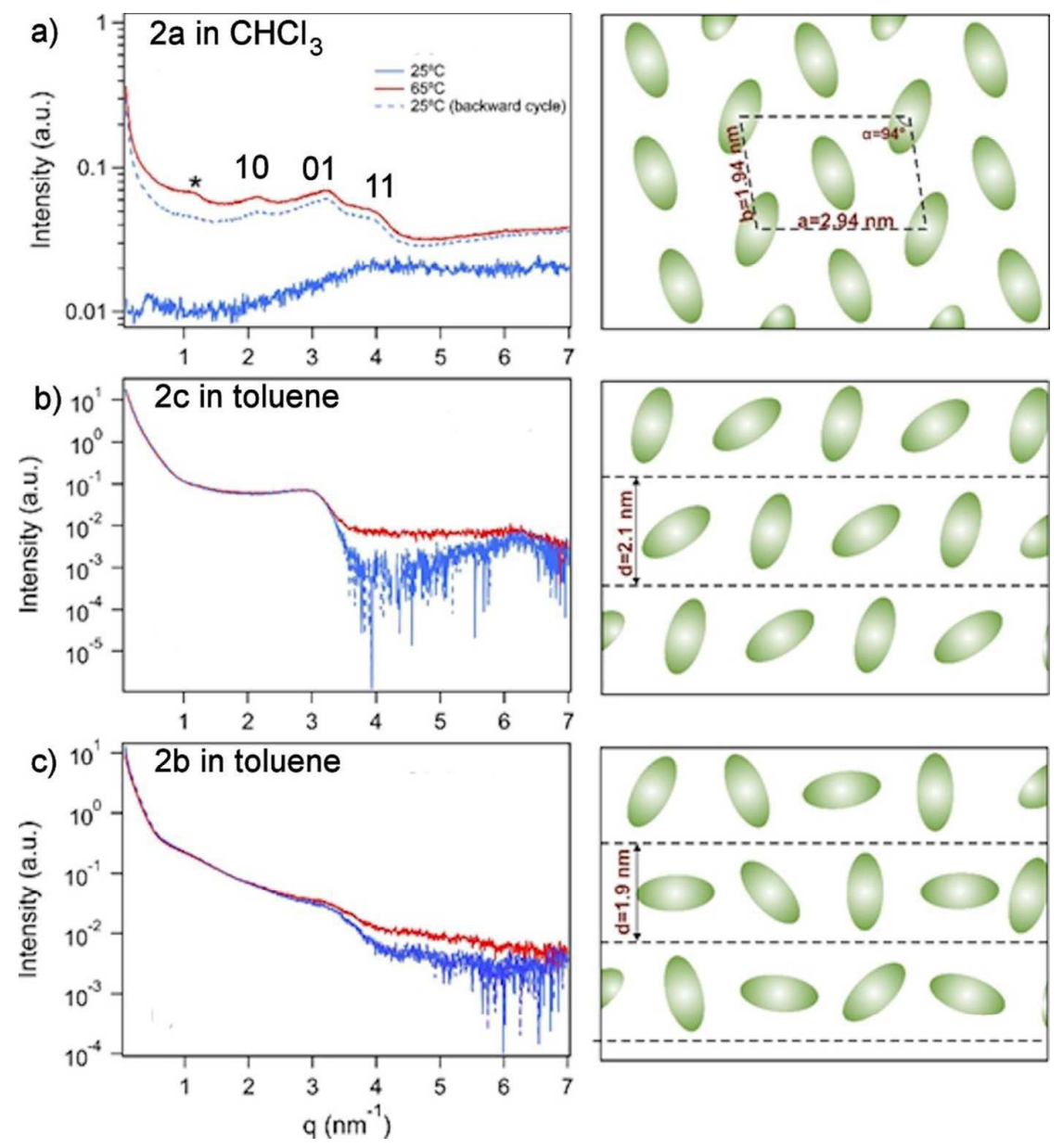

Figure 9. SAXS pattern of a) $\mathbf{2 a}$ in $\mathrm{CHCl}_{3}$, b) $\mathbf{2} \mathbf{c}$ in toluene and c) $\mathbf{2 b}$ in toluene, and their structural interpretation (right hand side). Pattern recorded at initially $25^{\circ} \mathrm{C}$ (blue), at $65^{\circ} \mathrm{C}$ (red) and after cooling back to $25^{\circ} \mathrm{C}$ (blue dashed) are shown. For 2a, the two-dimensional index assignments of the main peaks are shown. $*$ indicates a peak that could not be assigned, and was visible at high temperature only. 


\section{Conclusion}

The four amino acid-functionalised triphenylenes $\mathbf{2 a - 2 d}$ have been successfully prepared and characterized. The synthetic approach developed should allow for the preparation of other functionalised triphenylenes in a modular fashion. The glycine derivative $\mathbf{2 a}$ is a good gelator of chloroform, the alanine derivative $\mathbf{2 b}$ gels ethanol and toluene, the phenylalanine derivative $\mathbf{2 c}$ gels benzene and toluene, but the tryptophan derivative $\mathbf{2 d}$ does not gel any of the solvents tested. For $\mathbf{2 a}$ in $\mathrm{CHCl}_{3}$, concentration- and temperature-dependent ${ }^{1} \mathrm{H} \mathrm{NMR}$ suggests aggregation is driven by $\pi-\pi$ interactions rather than hydrogen bonds, since the aromatic protons (and protons close to the aromatic core) undergo significantly greater changes in chemical shift upon aggregation than the amide protons. The changes in absorbance and emission spectra on aggregation are small, but supportive of $\pi$ - $\pi$ interactions in the gelling solvents (by analogy with the case of TP6EO2M in water). Further, X-ray studies on the dried xerogel, and SAXS on the wet gel in its lyotropic state, argue persuasively for a disordered columnar oblique mesophase. This phase is relatively unusual in lyotropic liquid crystal systems, hexagonal mesophases being more commonly observed. 2a may therefore be of interest, for the templating of novel porous structures for example.

For $\mathbf{2 b}$ in toluene, NMR evidence suggests the aromatic core of the molecule is again involved in aggregation, but the side-chains (and the amide proton in particular) are more intimately involved than for $\mathbf{2 a}$ in $\mathrm{CHCl}_{3}$, implying a different type of structure. The fibres formed by $\mathbf{2 b}$ and $\mathbf{2} \mathbf{c}$ in toluene are narrower, and self-supporting gels form at higher concentrations. FTIR indicates the amide groups in both compounds are involved in stronger hydrogen-bonding in the gelling solvents than in non-gelling ones. SAXS suggests less ordered structures however, for $\mathbf{2 b}$ and $\mathbf{2 c}$, than for $\mathbf{2 a}$. These could be columnar aggregates with loose linear coupling between columns, since only a 1D lattice was observed. The 2D columnar organisation may be disrupted by more bulky side-chains. Consequently, work is underway to investigate mixtures of $\mathbf{2} \mathbf{b}$ or $\mathbf{2} \mathbf{c}$ with the less bulky derivative $\mathbf{2 a}$. We are also investigating the influence of the chirality of the side-chains for $\mathbf{2 b}, \mathbf{2 c}$ and $\mathbf{2 d}$ (in the current work, only the L-amino acid derivatives have been used, but we anticipate that the racemic compounds, and mixtures of L- and D- derivatives, may assemble differently. Further work aims to elucidate more fully the structures of the organogels, as well as the microspheres formed during evaporation of solutions of $\mathbf{2 d}$, to extend the range of compounds, and to investigate their optoelectronic and templating applications.

\section{Acknowledgements}

This work was supported by the EPSRC (Doctoral Training Grant to JM), HEFCE (Overseas Research Scholar award to XY), the Royal Thai government (Scholarship to RR) and the University of Leeds. The authors are grateful to Dr. Andrew Brown and Dr. John Harrington (both School of Chemical and Process Engineering, University of Leeds) for assistance with SEM, Simon Barrett (School of Chemistry, University of Leeds) for assistance with NMR, and to Dr. Leon Lever (School of Electronic and Electrical Engineering, University of Leeds) for helpful discussions. 


\section{References}

1. J. Billard, J. C. Dubois, N. Huutinh and A. Zann, Nouv. J. Chim., 1978, 2, 535.

2. D. Adam, P. Schuhmacher, J. Simmerer, L. Haussling, K. Siemensmeyer, K. H. Etzbach, H. Ringsdorf and D. Haarer, Nature, 1994, 371, 141.

3. M. Gupta and S. K. Pal, Langmuir, 2016, 32, 1120.

4. L. Zhang, D. L. Hughes and A. N. Cammidge, J. Org. Chem., 2012, 77, 4288.

5. M. Mansueto, S. Sauer, M. Butschies, M. Kaller, A. Baro, R. Woerner, N. H. Hansen, G. Tovar, J. Pflaum and S. Laschatt, Langmuir, 2012, 28, 8399.

6. V. Bhalla, H. Singh, M. Kumar and S. K. Prasad, Langmuir, 2011, 27, 15275.

7. K. Kawata, Chem. Record, 2002, 2, 59.

8. Z. Shen, M. Yamada and M. Miyake, J. Amer. Chem. Soc., 2007, 129, 14271.

9. M. Hara, S. Nagano and T. Seki, J. Amer. Chem. Soc., 2010, 132, 13654.

10. K. Tao, D. R. Lu, R. K. Bai, H. F. Li and L. J. An, Macromol. Rapid Comm., 2008, 29, 1477.

11. C. Givelet, B. Tinant, L. Van Meervelt, T. Buffeteau, N. Marchand-Geneste and B. Bibal, J. Org. Chem., 2009, 74, 652.

12. O. Hayashida, T. Matsuo, K. Nakamura and S. Kusano, J. Org. Chem., 2016, 81, 4196.

13. N. Boden, R. Bushby, C. Hardy and F. Sixl, Chem. Phys. Lett., 1986, 123, 359.

14. R. Hughes, A. Smith, R. Bushby, B. Movaghar and N. Boden, Mol. Crys. Liqu. Crys., 1999, 332, 547.

15. A. Akinshina, M. Walker, M. R. Wilson, G. J. T. Tiddy, A. J. Masters and P. Carbone, Soft Matter, 2015, 11, 680.

16. J. Barbera, A. C. Garces, N. Jayaraman, A. Omenat, J. L. Serrano and J. F. Stoddart, Adv. Mater., 2001, 13, 175.

17. M. Ikeda, M. Takeuchi and S. Shinkai, Chem. Commun., 2003, 1354.

18. T. Ishi-i, T. Hirayama, K. Murakami, H. Tashiro, T. Thiemann, K. Kubo, A. Mori, S. Yamasaki, T. Akao, A. Tsuboyama, T. Mukaide, K. Ueno and S. Mataka, Langmuir, 2005, 21, 1261.

19. K. Tao, T. Y. Wu, D. R. Lu, R. Bai, H. F. Li and L. J. An, J. Molec. Liqu., 2008, 142, 118.

20. Y. Tatewaki, T. Hatanaka, M. Kimura and H. Shirai, Chem. Lett., 2009, 38, 900.

21. Y. F. Bai, K. Q. Zhao, P. Hu, B. Q. Wang and Y. Shimizu, Mol. Crys. Liqu. Crys., 2009, 509, 802.

22. A. Kotlewski, B. Norder, W. F. Jager, S. J. Picken and E. Mendes, Soft Matter, 2009, 5, 4905.

23. M. Kaller, C. Deck, A. Meister, G. Hause, A. Baro and S. Laschat, Chem.- Eur. J., 2010, 16, 6326.

24. K. Tao, R. Bai, X. L. Zhao, Y. X. Wang, J. X. Li and L. Xue, Macromol. Chem. Phys., 2011, 212, 1016.

25. I. Munoz Resta, V. E. Manzano, F. Cecchi, C. C. Spagnuolo, F. D. Cukiernik and P. H. Di Chenna, Gels, 2016, 2.

26. M. Kimura, T. Hatanaka, H. Nomoto, J. Takizawa, T. Fukawa, Y. Tatewaki and H. Shirai, Chem. Mater., 2010, 22, 5732. 
27. Y. Hirai, M. H., N. Mizoshita, M. Moriyama, K. Hanabusa, Y. Shimizu and T. Kato, Adv. Funct. Mater., 2008, 18, 1668; N. Mizoshita, H. Monobe, M. Inoue, M. Ukon, T. Watanabe, Y. Shimizu, K. Hanabusa and T. Kato, Chem. Commun., 2002, 428.

28. N. M. Sangeetha and U. Maitra, Chem. Soc. Rev., 2005, 34, 821.

29. S. Ghosh, V. K. Praveen and A. Ajayaghosh, Ann. Rev. Mater. Res., 2016, 46, 235; S. Santosh Babu, V. K. Praveen and A. Ajayaghosh, Chem. Rev., 2014, 114, 1973; A. Ajayaghosh and V. K. Praveen, Acc. Chem. Res., 2007, 40, 644.

30. A. K. Das, P. P. Bose, M. G. B. Drew and A. Banerjee, Tetrahedron, 2007, 63, 7432.

31. S. Bai, S. Debnath, N. Javid, P. W. J. M. Frederix, S. Fleming, C. Pappas and R. V. Ulijn, Langmuir, 2014, 30, 7576; E. R. Draper, R. Schweins, R. Akhtar, P. Groves, V. Chechik, M. A. Zwijnenburg and D. A. Adams, Chem. Mater., 2016, 28, 6336; G. L. Eakins, J. P. Wojciechowski, A. D. Martin, J. E. A. Webb and J. M. Hodgkiss, Supramol. Chem., 2015, 27, 746.

32. D. K. Maiti and A. Banerjee, Chem.-Asian J., 2013, 8, 113; G. Palui and A. Banerjee, J. Phys. Chem. B, 2008, 112, 10107; S. Basak, J. Nanda and A. Banerjee, Chem. Commun., 2013, 49, 6891.

33. F. Krebs, N. C. Schiodt, W. Batsberg and K. Bechgaard, Synthesis, 1997, 1285.

34. A. R. Pujol, S. Bataille and A. Gourdon, Eur. J. Org. Chem., 2016, 176.

35. M. Lipowska, L. Hansen, X. Xu, P. A. Marzilli, A. Taylor Jr and L. G. Marzilli, Inorg. Chem., 2002, 41, 3032.

36. E. D. Kaverzneva, V. K. Zorykina and V. V. Kiseleva, Izv. Akad. Nauk SSSR, Ser. Khim., 1970, 10, 2295.

37. S. Zhang, K. Wu, M. C. Biewer and A. D. Sherry, Inorg. Chem., 2001, 40, 4284.

38. L.-O. Palsson, R. Pal, B. S. Murray, D. Parker and A. Beeby, Dalton Trans., 2007, 5726.

39. B. C. Gibb, A. R. Mezo, A. S. Causton, J. R. Fraser, F. C. S. Tsai and J. C. Sherman, Tetrahedron, 1995, 51, 8719.

40. E. Pop, M. E. Brewster, K. Tatrai-Prokai and N. Bodor, Heterocycles, 1994, 38, 2051.

41. V. Noponen, A. Valkonen, M. Lahtinen, H. Salo and E. Sievanen, Supramol. Chem., 2013, 25, 133; S. Maity, S. Nir and M. Reches, J. Mater. Chem. B, 2014, 2, 2583; S. M. M. Reddy, G. Shanmugam and A. B. Mandal, Org. Biomol. Chem., 2014, 12, 6181; K. Lv, L. Zhang and M. Liu, Langmuir, 2014, 30, 9295; J. Zhang, N.-W. Wu, X.-D. Xu, Q.-J. Li, C.-H. Wang, H. Tan and L. Xu, RSC Advances, 2014, 4, 16047; C.-C. Tsai, K.-C. Chang, I.-T. Ho, J.-H. Chu, Y.-T. Cheng, L.-C. Shen and W.-S. Chung, Chem. Commun., 2013, 49, 3037; C.-E. Chou, Y. Li, Y. Che, L. Zang and Z. Peng, RSC Advances, 2013, 3, 20666; D. Wang, J. F. Hsu, M. Bagui, V. Dusevich, Y. Wang, Y. Liu, A. J. Holder and Z. Peng, Tetr. Lett., 2009, 50, 2147.

42. Y. Lan, M. G. Corradini, R. G. Weiss, S. R. Raghavan and M. A. Rogers, Chem. Soc. Rev., 2015, 44, 6035.

43. M. Kastler, W. Pisula, D. Wasserfallen, T. Pakula and K. Mullen, J. Amer. Chem. Soc., 2005, 127, 4286.

44. S. Marguet, D. Markovitski, P. Millie, H. Sigal and S. Kumar, J. Phys. Chem. B, 1998, 102, 4697.

45. S. Shinkai, M. Takeuchi and M. Ikeda, Chem. Commun., 2003, 1354.

46. T. Jiao, Q. Huang, Q. Zhang, D. Xiao, J. G. Zhou and F. Gao, Nano. Res. Lett., 2013, 8, 278.

47. B. Mu, B. Wu, S. Pan, J. L. Fang and D. Z. Chen, Macromol., 2015, 48, 2388. 
Novel triphenylene derivatives form fibrous gels: SAXS on a wet gel shows these comprise 1-D stacks in a Colo arrangement.

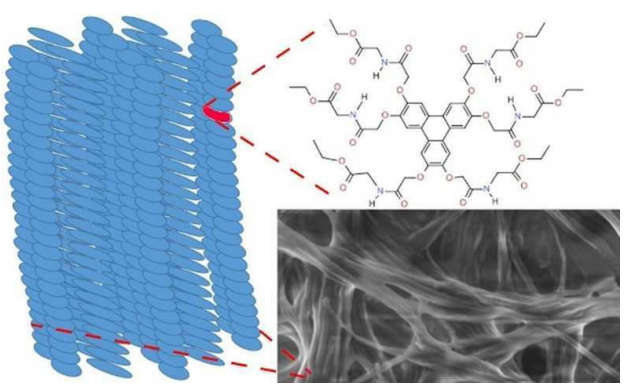

